\title{
Adulterants and Diluents in Heroin, Amphetamine, and Cocaine Found on the Illicit Drug Market in Aarhus, Denmark
}

\author{
Mette Findal Andreasen*, Christian Lindholst and Elisabet Kaa
}

Department of Toxicology and Drug Analysis, Institute of Forensic Medicine, University of Aarhus, Denmark

\begin{abstract}
The aim of the present study was to investigate the composition of heroin, amphetamine, and cocaine seized in the police district of Aarhus, the second largest city in Denmark, during a 2-year period. The purity of the active substance was measured together with the frequency and purity of adulterants and diluents present in the drugs. Results are compared with a similar study conducted ten years earlier. The concentrations of the active substances in illicit heroin, amphetamine, and cocaine samples have decreased significantly over a 10-year period. This finding shows that the "cutting" of illicit drugs is more prevalent and comprehensive today than it was 10 years ago. Also, the variety and quantity of adulterants and diluents have changed over time.
\end{abstract}

\section{INTRODUCTION}

In Denmark, illicit drugs are rarely sold or used in their pure state [1]. They are often mixed with other substances to provide a more manageable dosage unit [2]. Heroin, amphetamine, and cocaine are often extensively mixed or "cut" with a variety of substances, adulterants and/or diluents, in order to make it appear that there is larger amount of drug than is actually present, thereby increasing the dealer's profit [3-5]. Identification of potentially dangerous substances contaminating illicit drugs is important because these substances might be more toxic than the drug itself. For example, cocaine adulterated with atropine [6] or phenytoin [7] are examples of dangerous mixtures sold on the European drug market. Detailed knowledge and understanding of cutting agents found in street drugs may provide information about distribution routes [8]. The composition of cutting agents can also support comparative analysis linking two or more samples together [2]. Knowledge of possible changes in the prevalence of these substances is therefore important. Previous studies on adulterants and diluents seized in Denmark have demonstrated continually shifting patterns in the utilization and distribution of different cutting substances [3, 5, 9].

The aim of this study is to describe the purity and content of adulterants and diluents in hard drugs on the illicit drug market in Aarhus, Denmark's second largest city. This study covers cases in which drugs were seized in the Police District of Aarhus over a 2-year period, from 2002-2003. By comparing our results to those of a similar study conducted 10 years earlier, from 1992-1993 [10], changes in the illicit drug market were identified. The study described in this paper is part of a more comprehensive study describing the illicit drug market and the people involved $[1,11]$.

*Address correspondence to this author at the Institute of Forensic Medicine, University of Aarhus, Brendstrupgaardsvej 100, DK-8200 Aarhus N, Denmark; Tel: +45 8942 9844; Fax: + 45 86175003;

E-mail: mfa@forensic.au.dk

\section{MATERIALS AND METHODS}

\section{Samples}

Sample material was taken from hard drugs seized in the Police District of Aarhus during a 2-year period from January $1^{\text {st }} 2002$ to December $31^{\text {st }} 2003$. During this period, the police seized 150 heroin samples, 163 amphetamine samples and 169 cocaine samples suitable for study. All samples were subjected to chemical analysis in which the identity, purity, weight, and appearance (powder, colour, etc.) of the illicit drug were analysed. The Police District of Aarhus covered an area of $860 \mathrm{~km}^{2}$ and had 333,561 inhabitants when the investigation ended on $1^{\text {st }}$ January 2004.

\section{Methods}

All analytical methods used in this study were validated and accredited in accordance with the requirements of the DS/EN ISO/IEC 17025 standard. Accreditation was provided by an external, independent organization, DANAK (Danish Accreditation), which handles the administration of accreditation and metrology in Denmark. All samples were dried, homogenised and dissolved in appropriate buffers prior to analysis. A preliminary qualitative GC-MS screening was conducted on all samples in order to identify the controlled substances as well as any adulterants. A subsequent quantitative HPLC-DAD analysis was conducted, using appropriate reference standards, in order to measure the concentration of the drug, heroin, amphetamine or cocaine, and the concentrations of the adulterants. The chemical formulation (chloride, sulphate or base) was confirmed using precipitation tests with silver nitrate and barium chloride solutions. Sugar diluents were quantified using an HPLC-RI method. This method was not able to discriminate between lactose and maltose, thus a positive test for either substance was noted as detection of lactose/maltose. Quantification was performed with an average of two standards.

\section{Terminology}

All purities were expressed in terms of weight/weight percentages. Illicit drug purity was expressed in terms of the free base, even though all amphetamine samples were pre- 
sent as sulphate and all cocaine samples were in the form of hydrochloride. In terms of weight \%, $100 \%$ amphetamine sulphate is equivalent to $73 \%$ amphetamine base, $100 \%$ cocaine hydrochloride is equivalent to $89 \%$ cocaine base and $100 \%$ heroin hydrochloride is equivalent to $87 \%$ heroin base. Adulteration was defined as the introduction of a pharmacologically active substance to the illicit drug. The adulterating substance may have a physiological effect resembling that of the active substance, thereby disguising the lower concentration of active substance that is present. Diluents were defined as substances without a pharmacological effect that were added to illicit drugs. Sugars, such as lactose, sucrose and glucose, are often used for dilution purposes. The physical appearance of sugar is often similar to that of the active substance, and sweetening may give the end product a more pleasant taste [5]. Mannitol and inositol are in this study considered sugar diluents. Mannitol is a sugar alcohol and is half as sweet as sugar. Inositol is a carbocyclic polyol also called meat sugar.

\section{Statistics}

Two-sample t-tests were used to assess differences in the purities of the controlled substances between the samples collected from 1992-1993 and those from 2002-2003. All probability values were reported as two-tailed probability values, and $p<0.05$ was taken as the level of significance.

\section{RESULTS}

\section{Heroin}

This study included 150 heroin samples (146 heroin base and 4 heroin hydrochloride samples). The concentration of diacetylmorphine in the heroin base samples varied from 3 $\%$ to $51 \%$ with a mean purity of $23 \%$ (Table 1). Analysis of the adulterants was possible for 132 samples, as the other samples did not have enough material for this analysis. All of these samples analysed were adulterated. Caffeine and paracetamol were the most frequently used adulterants found in $99 \%$ and $97 \%$ of the samples, respectively (Table 2).

Table 1. Purity of Illicit Hard Drugs Seized in Aarhus, Denmark. Average Concentration and Range in 1992-1993 [10] and in 2002-2003

\begin{tabular}{|c|c|c|c|c|}
\hline & \multicolumn{2}{|c|}{ Average Concentration ${ }^{1}(\%)$} & Range $(\%$ min. - max $)$ \\
\hline Drug & $\mathbf{1 9 9 2 - 1 9 9 3}$ & $\mathbf{2 0 0 2 - 2 0 0 3}$ & $\mathbf{1 9 9 2 - 1 9 9 3}$ & $\mathbf{2 0 0 2 - 2 0 0 3}$ \\
\hline \hline Heroin base & $33(\mathrm{n}=146)$ & $23 *(\mathrm{n}=146)$ & $0.5-68$ & $3-51$ \\
\hline Heroin hydrochloride & $51(\mathrm{n}=19)$ & $63(\mathrm{n}=4)$ & $15-87$ & $46-83$ \\
\hline Amphetamine sulphate & $21(\mathrm{n}=194)$ & $13 *(\mathrm{n}=163)$ & $0.7-73$ & $0.1-70$ \\
\hline Cocaine hydrochloride & $60(\mathrm{n}=13)$ & $35 *(\mathrm{n}=169)$ & $13-88$ & $0.3-78$ \\
\hline
\end{tabular}

${ }^{1}$ Average concentration $(\% \mathrm{w} / \mathrm{w})$ of the active base. * Significantly $(\mathrm{p}<0.05)$ lower purity in 2002-2003 than in $1992-1993$.

Table 2. Frequency, Average Concentration and Variation of Adulterants and Diluents found in Heroin Base Samples from 20022003 Compared to Data from 1992-1993 [10]

\begin{tabular}{|c|c|c|c|c|c|}
\hline & & \multicolumn{2}{|c|}{ Frequency ( \%) } & \multirow{2}{*}{ Concentration $(\%)^{1} 2002-2003$} & \multirow{2}{*}{ Range (\% min. - max.) 2002-2003 } \\
\hline & & $1992-1993(n=146)$ & $2002-2003(n=132)$ & & \\
\hline \multirow[t]{11}{*}{ Adulterants: } & Caffeine & 78 & 99 & 22 & $0.2-41$ \\
\hline & Paracetamol & 62 & 97 & 27 & $0.2-53$ \\
\hline & Griseofulvin & n.d. & 26 & 2 & $0.1-16$ \\
\hline & Diazepam & 2 & 1 & - & - \\
\hline & Phenobarbital & 16 & n.d. & - & - \\
\hline & Piracetam & 8 & n.d. & - & - \\
\hline & Methaqualone & 8 & n.d. & - & - \\
\hline & Procaine & 5 & n.d. & - & - \\
\hline & Barbital & 4 & n.d. & - & - \\
\hline & Ascorbic acid & $<1$ & n.d. & - & - \\
\hline & Salicylic acid & $<1$ & n.d. & - & - \\
\hline \multirow[t]{4}{*}{ Sugar diluents: } & Mannitol & 8 & 2 & $<6$ & $<6$ \\
\hline & Sucrose & 5 & 2 & 12 & $<6-15$ \\
\hline & Glucose & 32 & n.d. & - & - \\
\hline & Lactose/maltose & 18 & n.d. & - & - \\
\hline
\end{tabular}

${ }^{1}$ Average concentration $(\% \mathrm{w} / \mathrm{w})$ of the active base; n.d.: not detected; < : substance detected but at a concentration less than the methods LOQ (limit of quantification). 
Only $5 \%$ of the heroin base samples were diluted with sugar (Table 2). All heroin base samples contained the opium alkaloids morphine, codeine, papaverine, and noscapine and the synthesis products monoacetylmorphine (MAM) and acetylcodeine in varying concentrations (results not shown). Only four heroin hydrochloride samples were analysed in the study and the concentration of diacetylmorphine in these samples varied from $46 \%$ to $83 \%$, with a mean concentration of $63 \%$. No adulterants were detected in any of the heroine hydrochloride samples. Analysis of diluents was only possible in two of the samples. One contained $40 \%$ glucose and the other contained $23 \%$ glucose and $11 \%$ lactose/maltose.

\section{Amphetamine}

In this study, 163 amphetamine samples were analyzed. The chemical formulation was determined for 159 of the samples, as the other samples did not have enough material for this analysis. All of the analysed samples contained amphetamine sulphate. The concentration of amphetamine sulphate ranged from 0.1 to $70 \%$ active substance with a mean purity of $13 \%$ (Table 1). Of the samples 141 had enough material for the analysis of adulterants, of these $77 \%$ contained adulterants and 6 different adulterants were used. Caffeine was the most frequently used adulterant, as it was found in $58 \%$ of the samples (Table 3). Sugar was used as a diluent in $89 \%$ of the amphetamine samples. Five different sugars were used.

\section{Cocaine}

This study analysed 169 cocaine samples of which the chemical formulation was determined for 165 of the samples that had enough material for this analysis. They all contained cocaine hydrochloride. Free base "crack" was not found in any of the samples. The purity of cocaine hydrochloride varied from 0.3 to $78 \%$, with a mean purity of $35 \%$ (Table 1).
Adulterants were analysed in 147 of the samples. Of these, $87 \%$ contained adulterants, and 11 different substances were identified. Lidocaine was the most commonly used adulterant (Table 4). Sugar diluents were found in $95 \%$ of the cocaine samples and 5 different sugar diluents were used. Cocaine samples contained up to $87 \%$ sugar diluents by weight (Table 4).

\section{Changes Over a 10-year Period}

Comparison of the results obtained from analyses of the illicit drugs obtained during the 2-year study period (20022003) with those from a similar study conducted 10 years earlier (1992-1993 [10]) indicates that the average purities of heroin base, amphetamine and cocaine have decreased significantly over time (Table 1). The average purity of heroin base decreased by $30 \%$, from a mean purity of $33 \%$ to $23 \%$; the mean purity of amphetamine sulphate decreased by $36 \%$, from $21 \%$ to $13 \%$; and the mean purity of cocaine hydrochloride decreased by $42 \%$, from $60 \%$ to $35 \%$.

Only 4 adulterants were used in heroin base samples seized from 2002-2003, while 11 adulterants were used from 1992-1993 (Table 2). Usage of the two most common heroin adulterants, caffeine and paracetamol, increased in frequency from $78 \%$ to $99 \%$ and from $62 \%$ to $97 \%$, respectively. Griseofulvin was not identified in the 1992-1993 study; however, it was found in $26 \%$ of the heroin base samples seized from 2002-2003. Approximately $50 \%$ of the heroin base samples confiscated from 1992-1993 were diluted with sugar; however, only $5 \%$ of the samples from 2002-2003 contained sugar (mannitol and sucrose). Furthermore, the sugar contained in the samples from 2002-2003 was present in low concentrations. The average heroin base sample from 2002-2003 contained only $0.2 \%$ sugar.

During the 1992-1993 study, 3 adulterants were identified in amphetamine samples, compared to 6 adulterants

Table 3. Frequency, Average Concentration and Variation of Adulterants and Diluents found in Amphetamine Samples from 2002-2003 Compared to Data from 1992-1993 [10]

\begin{tabular}{|c|c|c|c|c|c|}
\hline & & \multicolumn{2}{|c|}{ Frequency ( \%) } & \multirow{2}{*}{ Concentration $(\%)^{1} 2002-2003$} & \multirow{2}{*}{ Range (\% min. - max.) 2002-2003 } \\
\hline & & $1992-1993(n=194)$ & $2002-2003(n=140)$ & & \\
\hline \multirow{4}{*}{ Adulterants: } & Creatine & n.a. & 34 & 23 & $4-51$ \\
\hline & Ephedrine & n.d. & 6 & 3 & $0.8-6$ \\
\hline & Paracetamol & 4 & 3 & 6 & $2-16$ \\
\hline & Phenazone & 10 & 3 & 5 & $0.1-9$ \\
\hline \multirow[t]{3}{*}{ Sugar diluents: } & Lactose/maltose & 58 & 65 & 32 & $<9-79$ \\
\hline & Sucrose & 9 & 39 & 35 & $<6-74$ \\
\hline & Fructose & n.d. & 1 & $<8$ & $<8$ \\
\hline
\end{tabular}

${ }^{1}$ Average concentration ( $\%$ w/w) of the active base; n.a.: not analysed: not detected; < : substance detected but at a concentration less than the methods LOQ (limit of quantification). 
Table 4. Frequency, Average Concentration and Variation of Adulterants and Diluents found in Cocaine Samples (n =147) from 2002-2003

\begin{tabular}{|c|c|c|c|c|}
\hline & & Frequency $(\%)$ 2002-2003 & Concentration $(\%)^{1} 2002-2003$ & Range (\% min. - max.) $2002-2003$ \\
\hline \multirow[t]{7}{*}{ Adulterants: } & Lidocaine & 65 & 11 & $0.3-36$ \\
\hline & Caffeine & 24 & 3 & $0.1-54$ \\
\hline & Creatine & 22 & 24 & $5-40$ \\
\hline & Paracetamol & 3 & 21 & $11-35$ \\
\hline & Benzocaine & 3 & n.a. & n.a. \\
\hline & Phenazone & 1 & n.a. & n.a. \\
\hline & Ephedrine & 1 & n.a. & n.a. \\
\hline \multirow{4}{*}{ Sugar diluents: } & Inositol & 41 & 38 & $<8-87$ \\
\hline & Sucrose & 31 & 31 & $<6-60$ \\
\hline & Lactose/maltose & 24 & 24 & $<9-50$ \\
\hline & Glucose & 22 & 23 & $<8-44$ \\
\hline
\end{tabular}

${ }^{1}$ Average concentration ( $\%$ w/w) of the active base; n.a.: not analysed; < : substance detected but at a concentration less than the methods LOQ (limit of quantification). Frequencies of cocaine adulterants from 1992- 1993 were not included due to the limited number samples [10].

found in the 2002-2003 study. Ephedrine and salicylamide were not seen in samples from 1992-1993 and creatine was not analysed in the 1992-1993 study. The frequency of samples diluted with sugar did not change during this 10-year period. Sugar diluents were used in $89 \%$ of the samples from both periods. Glucose was the most commonly used sugar diluent from 1992-1993, while lactose/maltose was the most frequently used sugar from 2002-2003. Because cocaine was not prevalent in the 1992-1993 period, there were too few cocaine samples analyzed from this period to allow for a meaningful comparison with the current findings.

\section{DISCUSSION}

Unexpected adulterants and unpredictable drug purities can endanger the lives of drug users. The purpose of the present investigation was to study the compositions of heroin, cocaine and amphetamine samples, as these drugs are the most frequently encountered hard drugs (excluding cannabis) on the market in Denmark [11]. Large variations in the quality of these illicit drugs, measured in terms of the concentration of active substance, were observed. The study included drug samples of nearly $100 \%$ purity, which were neither diluted nor adulterated. For example, an amphetamine sample with a concentration of $70 \%$ active base (corresponding to $96 \%$ amphetamine sulphate) was seized. In contrast, other samples had such low concentrations of the active drugs that any pharmacological effect was doubtful. For example, cocaine samples with concentrations of $0.3 \%$ active drug and amphetamine samples with concentrations of $0.1 \%$ active base were seized. These large variations in concentration pose risks to the health of the end users, since a formal declaration of purity does not accompany the illicit drug.
Heroin base samples were extensively adulterated with caffeine and paracetamol. Caffeine was probably added to the heroin because of its stimulatory effect. Furthermore, caffeine has synergistic effects with heroin, as it improves the uptake of diacetylmorphine during heroin base smoking [12]. Paracetamol has an analgesic effect and is sold as an over-the-counter drug, which is easy to obtain. Griseofulvin was often seen in samples of heroin base. This is an antifungal drug used in animals and humans to treat ringworm infections of the skin and nails. Why it is added to heroin is not fully understood, but the drug has a bitter taste, which resembles that of heroin.

The low presence of sugar diluents in heroin base samples distinguished them from amphetamine and cocaine samples, since approximately $95 \%$ and $89 \%$ of these, respectively, contained sugar diluents. The low presence of sugar in heroin base may reflect the fact that heroin is often smoked. It is not suitable to smoke a substance containing sugar. Heroin hydrochloride is usually found as a white powder, whereas heroin base is usually light brown. The heroin hydrochloride samples examined in this study had much higher purity than the samples that contained heroin base. While no adulterants were found in the heroin hydrochloride samples, all of the heroin base samples were adulterated. Conversely, all of the heroin hydrochloride samples that were analysed for diluents were found to be diluted with sugar, whereas only $5 \%$ of the heroin base samples were similarly cut. Nevertheless, the data presented here are too limited to be conclusive.

Most illicit amphetamine is adulterated and/or extensively diluted before reaching the end user. In this study, 
$77 \%$ of the amphetamine samples contained an adulterant and 6 different adulterants were used. Caffeine and creatine were the most frequently used adulterants. Caffeine has a stimulatory effect, which resembles that of amphetamine. Creatine is easy to obtain, because it is a legal substance that is widely used to enhance athletic performance. Moreover, the appearance of creatine resembles that of amphetamine in the powder form. The amphetamine samples were also diluted with sugar and an average amphetamine sample contained approximately $35 \%$ sugar.

In this investigation, the only identified formulation of cocaine was hydrochloride salt. The police did not seize any free base, although it is a known commodity on the illicit drug market (personal communication with the police). Cocaine was extensively adulterated and diluted with other substances. Adulterants were found in $87 \%$ of the samples and sugar diluents were found in $95 \%$ of the samples. Lidocaine is a local anaesthetic whose effects mimic those of cocaine. Addition of lidocaine to a sample gives drug users the impression that the cocaine is of higher quality. It was therefore not surprising to find that lidocaine was the most common cocaine adulterant found in $65 \%$ of the samples. Phenacetin, caffeine, and creatine were also frequently used as adulterants in cocaine. Phenacetin has an analgesic effect. The stimulatory effect of caffeine resembles that of cocaine. Creatine is easy to obtain and its appearance resembles that of cocaine. Procaine, paracetamol, benzocaine, phenazone, ephedrine, mirtazapine, and ketamine were seen in only a few samples. The use of some adulterants cannot be explained in terms of their pharmacological effects. Some adulterants appear on the market for only a short period of time and their inclusion in the product seems to be purely opportunistic in nature.
This study has demonstrated that heroin, amphetamine, and cocaine were extensively mixed with a variety of adulterants and diluents. Based on comparison of this data with those obtained in a similar study from 1992-1993, it is evident that drug purity has significantly decreased over time. To that end, these illicit drugs were more adulterated and/or diluted in 2002-2003 than they were in the period from 1992-1993.

\section{ACKNOWLEDGEMENTS}

The authors would like to acknowledge the local police in Aarhus for providing the drug samples. Sisse Elle Mikkelsen, Rasmus Telving, Inge Korup and Laila Kearney are acknowledged for their technical assistance.

\section{REFERENCES}

[1] Lindholst, C.; Andreasen, M.F.; Kaa, E. Ugeskr Lager, 2008, 170, 54-58.

[2] King, L.A. Forensic Sci. Int., 1997, 85, 135-147.

[3] Kaa, E. Forensic Sci. Int., 1994, 64, 171-179.

[4] Fucci, N.; Giovanni, N. Forensic Sci. Int., 1998, 95, 247-252.

[5] Kaa, E.; Kaempe, B. Forensic Sci. Int., 1986, 31, 195-210.

[6] Ridder, W.P.; Klimek, M.; Rupreht, J. Ned. Tijdschr. Geneeskd., 2005, 149, 1701-1703

[7] Katz, A.A.; Hoffman, R.S.; Silverman, R.A. Ann. Emerg. Med., 1993, 22, 1485-1487.

[8] Van der Slooten, E.P.; van der Helm, H. J. Forensic Sci., 1975, 6 , 83-88.

[9] Kaa, E. J. Forensic Sci., 1991, 36, 866-879.

[10] Kaa, E.; Bowmann, H. Det illegale stofmarked $i$ Arhus (The illicit drug market in Denmark); Aarhus University Press: Aarhus, Denmark, 1997.

[11] Lindholst, C.; Andreasen, M.F.; Kaa, E. Det illegale stofmarked $i$ Aarhus (The illicit drug market in Aarhus); Aarhus University Press: Aarhus, Denmark, 2008 170(1): 54-7.

[12] Huizer, H. Pharm. Weekbl., 1987, 9, 203-211. 